\title{
Ozone injections therapies for temporo-mandibular joint disorders/disfunctions [abstract]
}

\author{
Robert E Harris
}

The American College of Integrative Medicine and Dentistry, Louisville, Kentucky. USA

\section{ABSTRACT}

\section{OPEN ACCESS}

\section{Citation \\ Harris RE. Ozone injections therapies for temporo-mandibular joint disorders/ disfunctions [abstract]. Proceedings of The World Conference on Ozone Therapy in Medicine, Dentistry and Veterinary. Ancona (Italy). September 22nd - 23rd - 24th , 2017. J Ozone Ther. 2019;3(4):25. doi: 10.7203/ jo3t.3.4.2019.15505}

\section{Academic Editor \\ Jose Baeza-Noci, \\ School of Medicine, Valencia University, SPAIN}

\section{Editor}

World Federation of Ozone Therapy, Bolgna, ITALY

\section{Received}

June 17, 2019

\section{Accepted}

December 08, 2019

Published

December 30, 2019

\section{Intellectual Property}

Robert E Harris.

This is an open access article distributed under the terms of the Creative Commons Attribution License (CC BY 4.0), which permits unrestricted use, distribution, and reproduction in any medium, provided the original author and source are credited.

\section{Author Information}

rehdmd@gmail.com
Introduction: Temporomandibular Joint Disorders/Dysfunctions (TMJD) were first described in ancient Egyptian literature. The condition has been reported in the medical/dental literature under a variety terms and syndromes. TMJD is the currently accepted term for a variety of conditions in the head, neck and temporomandibular joint areas.

Materials and methods: A systematic review and search of the literature produced the following results:

$\begin{array}{lrr}\text { TMJ Infection } & 2,080,000 & \text { Google } \\ \text { TMJ Injections } & 32,900 & \text { Google } \\ \text { TM Joint } & 24,839 & \text { PubMed } \\ \text { TMJ Disorders } & 16,511 & \text { PubMed } \\ \text { TMJ Dysfunction } & 6,439 & \text { PubMed }\end{array}$

The information obtained from these sources in conjunction with clinical training was the basis for the development of the currently described protocols.

Results: The current treatment protocols for TM Joint injections utilize homeopathic solutions, B vitamins, procaine and gaseous ozone. These protocols have been used and modified since 2001. The results have demonstrated a significant reduction in the pain levels and improved function of the TM Joint.

Conclusion: Using gaseous ozone in therapeutic combinations of anesthetics, homeopathics and B vitamins have produced positive outcomes in the management of the majority of the very difficult to treat population of head, neck and TMJD patients.

\section{References:}

1. Semronio S. Septic arthritis of the temporomandibular joint successfully treated with arthroscopic lysis and lavage: a case report and review of the literature. Oral Surg Oral Med Oral Pathol Oral Radiol. 2007;103(2):e1-e6.

2. Gayle,EA 2013 Septic arthritis of the temporomandibular joint: case reports and review of the literature. J Emerg Med. 2013;45(5):674-678. 